University of Nebraska - Lincoln

DigitalCommons@University of Nebraska - Lincoln

Robert G. Fuller Publications and Presentations Research Papers in Physics and Astronomy

June 1969

\title{
Spectrophotometric System for Transient Observation of Solids under Pulsed Electron Irradiation
}

\author{
R.T. Williams \\ Naval Research Laboratory, Washington, D. C. \\ Robert Fuller \\ rfuller@neb.rr.com \\ M.N. Kabler \\ Naval Research Laboratory, Washington, D. C. \\ V.H. Ritz \\ Naval Research Laboratory, Washington, D. C.
}

Follow this and additional works at: https://digitalcommons.unl.edu/physicsfuller

Part of the Physics Commons

Williams, R.T.; Fuller, Robert; Kabler, M.N.; and Ritz, V.H., "Spectrophotometric System for Transient Observation of Solids under Pulsed Electron Irradiation" (1969). Robert G. Fuller Publications and Presentations. 16.

https://digitalcommons.unl.edu/physicsfuller/16

This Article is brought to you for free and open access by the Research Papers in Physics and Astronomy at DigitalCommons@University of Nebraska - Lincoln. It has been accepted for inclusion in Robert G. Fuller Publications and Presentations by an authorized administrator of DigitalCommons@University of Nebraska - Lincoln. 
used in this laboratory to investigate metastable color centers and excitons in alkali halide crystals at low temperature, ${ }^{1}$ and also transient color centers and associated luminescence in quartz, fused silica, and silicate glasses. ${ }^{2}$

This general type of measurement on alkali halide crystals has been carried out previously by several groups, ${ }^{3-5}$ using equipment which varied in detail but which all involved irradiations with electron linear accelerators at $2 \mathrm{MeV}$ or higher energies. The present approach differs from its predecessors in that it makes use of a much more compact, economical, and convenient irradiation source and employs an optical path which gives maximum absorption in samples for which the penetration depth of the radiation is small.

A portable commercial electron accelerator ${ }^{6}$ which is small enough to fit into one corner of an ordinary laboratory room is the radiation source. It operates by capacitor discharge through a field emission diode and delivers an electron pulse whose length at the half-current points is $3 \mathrm{nsec}$. The energy per pulse in the electron beam transmitted through the window of the electron tube is approximately $10 \mathrm{~J}$. The effective energy of this beam, obtained by calorimetry and glass-block dosimetry, ${ }^{7}$ is about $500 \mathrm{keV}$. Electrons of this energy deposit $90 \%$ of their energy in a layer $0.14 \mathrm{~g} / \mathrm{cm}^{2}$ thick in low atomic number materials. This corresponds to a depth of $\approx 0.05 \mathrm{~cm}$ in a typical alkali halide. The corresponding penetration in water would be $\approx 0.14 \mathrm{~cm}$.

In order to obtain an easily measurable optical density from this thin layer of coloration, the light beam is internally reflected at low angle from the target face of the crystal as shown in Fig. 1. The angle between the light beam and the target surface of a typical sample $(1.5 \times 1.5$ $\times 0.3 \mathrm{~cm})$ is approximately $14^{\circ}$. Hence, the length of the optical path in the irradiated volume of the sample is increased by more than a factor of 10 over the normal incidence path. In practice the enhancement in path length at ever decreasing angles must be balanced against the loss of light intensity, as the illuminated portion of the sample defines the effective slit for the optical system.

The samples are mounted in a standard cold-finger

\section{Spectrophotometric System for Transient Observation of Solids under Pulsed Electron Irradiation}

R. T. Williams, R. G. Fuller, M. N. Kabler, and V. H. Ritz Naval Research Laboratory, Washington, D. C. 20390

(Received 4 June 1969)

$T$ HE purpose of this note is to describe a relatively simple apparatus for measuring the properties of transient optical absorption and emission bands in solids under pulsed irradiation. The equipment is presently being

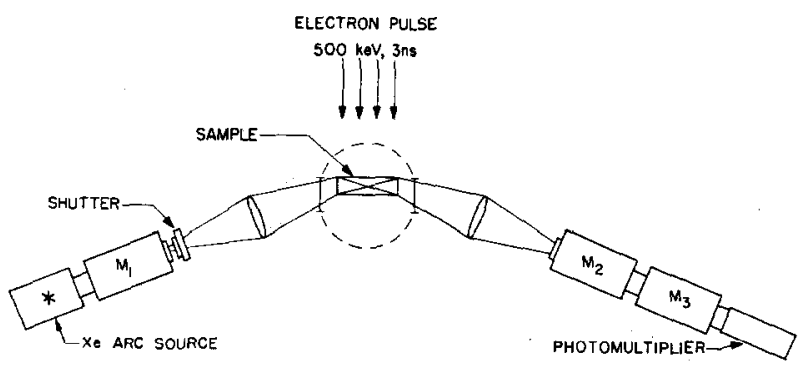

Fug. 1. Optical components of the spectrophotometric system. $\mathrm{M}_{1}, \mathrm{M}_{2}, \mathrm{M}_{3}-$ monochromators. 
for the electron beam. The electron beam traverses a $28 \mathrm{~cm}$ air path between the exit window of the electron accelerator and the titanium Dewar window. The sample is mounted in vacuum on the Dewar cold finger approximately $3 \mathrm{~cm}$ behind the Dewar window. Under these conditions a single electron pulse will deposit $10^{17} \mathrm{eV} / \mathrm{cm}^{2}$ in the sample. This generates an easily detected transient absorption if the analyzing light is internally reflected. In this way the dose per pulse is kept relatively low, and a large number of pulses are possible before the concentration of stable color centers builds up sufficiently to affect the transient response.

A dc xenon light source is focused onto the crystal through a grating monochromator and a fast photographic shutter. The shutter is synchronized with the electron pulse and serves to protect the photomultiplier from excessive average current and to avoid unwanted bleaching or heating effects in the sample. The two monochromators preceding the detector help discriminate against the very intense luminescence sometimes encountered in the vicinity of the transient absorption bands. Several alternative photomultiplier tubes have been used to cover the spectral range from 200 to $1100 \mathrm{~nm}$. The photomultiplier output is fed directly to an oscilloscope. In operation, the shutter is opened manually, and this triggers the oscilloscope which in turn triggers the accelerator.

A photograph of a typical oscilloscope display of transmission vs time is shown in Fig. 2. Transmission increases in the downward direction, starting from zero at the top line. The sample in this case is a $\mathrm{RbBr}$ crystal at liquid helium temperature, and the wavelength is $775 \mathrm{~nm}$. The absorption rises instantaneously (on this time scale) upon irradiation and decays exponentially with a lifetime of $180 \mu \mathrm{sec}$. It has been tentatively attributed to self-trapped excitons. ${ }^{1,9}$ The system is currently being operated primarily in the microsecond time range, but by flashing the xenon lamp to obtain higher peak light intensity it can be made to perform adequately at a time resolution of several nanoseconds. Luminescence measurements can be made during an absorption run by simply turning off the light source. Although heating by the electron pulse can

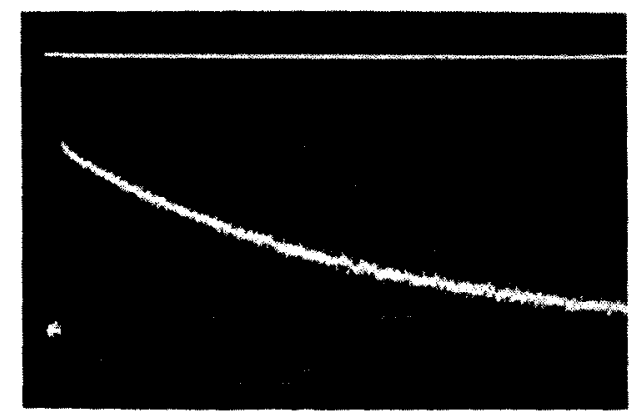

Fig. 2. Typical oscilloscope display. Vertical scale $100 \mathrm{mV} / \mathrm{div}$, horizontal scale $50 \mu \mathrm{sec} / \mathrm{div}$. cause important effects in crystals which are initially at liquid helium temperature, our experiments indicate an upper limit of $20 \mathrm{~K}$ for the temperature of the sample.

${ }^{1}$ R. G. Fuller, M. N. Kabler, and R. T. Williams, Bull. Amer. Phys. Soc. 14, 430 (1969).

${ }^{2}$ G. H. Sigel, Jr. and D. L. Griscom, Bull. Amer. Phys. Soc. 13, 1474 (1968)

${ }^{3}$ J. H. Schulman and J. W. Boag. Phys. Status Solidi 3, 516 (1963).

${ }^{4}$ M. Ueta, J. Phys. Soc. Japan 23, 1265 (1967).

${ }^{5}$ D. A. Patterson and R. G. Fuller, Phys. Rev. Lett. 18, 1123 (1967).

${ }^{6}$ Febetron 706 pulsed electron accelerator, Field Emission Corp., McMinnville, Oregon.

${ }^{7}$ V: H. Ritz and C. H. Cheek, Radiation Res. 25, 537 (1965).

${ }^{8}$ Obtainable from Hamilton Precision Metals, Lancaster, Pa.

${ }^{9} \mathrm{M}$. N. Kabler and D. A. Patterson, Phys. Rev. Lett. 19, 652 $(1967)$. 